\title{
An operational effectiveness evaluation method of the swarming UAVs air combat system
}

\author{
Niping Jia, Zhiwei Yang*, and Kewei Yang \\ College of System Engineering, National University of Defense Technology Changsha, Hunan, P.R. \\ China
}

\begin{abstract}
In this paper, we propose an operational effectiveness evaluation method of the swarming UAVs air combat system. The system network model is firstly established before the evaluation. We divide the edges in the network into nine types according to the Generalized Operation Loop and give the edge attribute of operational information entropy based on node attributes. When calculating the system operational effectiveness, we focus on the striking ability and propose the concept of Operation Loop Capability to represent the target-attack effectiveness of a certain operational loop, which can be calculated from the edge operational information entropies. We can get the combat effectiveness to a certain target from the Operation Loop Capability, and the combat effectiveness of the swarming UAVs air combat system is represented by the sum of the striking capabilities to all targets. Finally, the scene of swarming UAVs air combat is taken as a case study to apply and verify our evaluation method. This paper gives a quantitative perspective on swarming UAVs combat system assessment and can help to analyze the contribution of UAVs and other weapons in the system.
\end{abstract}

\section{Introduction}

Recently, the new battlefield concept of swarming unmanned aerial vehicles (UAVs) combat is getting world-wide attention. It is derived from the concept of the "distributed killing" capability, which is listed as one of the most significant abilities to be developed in the US "third offset strategy"[1], and it means decomposing the functions of large equipment by multiple small unmanned combat platforms.

At present, many scholars have introduced and analyzed the swarming UAVs air combat system [2][3]. But most of these studies are descriptive, lacking quantitative modeling and assessment of the swarming UAVs combat system, which is of great significance for UAVs development planning and weapon system requirement analyzation. However, the swarming UAV air combat system is also a typical military system, and there have been many literatures about the system modeling and evaluation issue. One important modeling and evaluation method is the network theory. American scholar Jeffery R. Cares proposed the IACM model and divided the operational nodes in the weapon network into

\footnotetext{
* Corresponding author: zhwyang88@hotmail.com
} 
four types [4][5]. The research team in National University of Defense Technology proposed a network description and evaluation method of the weapon system called Operation Loop (OL) [6]. They divided the system weapons into sensors, decision-makers, attackers and targets, which provided a good perspective for combat system modeling and evaluation.

Based on the present studies on military systems, in this paper, we propose an operational effectiveness evaluation method of the swarming UAVs air combat system through network modeling. This work gives a new perspective for modeling and assessing the swarming UAVs air combat system quantitatively.

\section{Network modeling of the swarming UAVs air combat system based on Generalized Operation Loop}

\subsection{The concept of Generalized Operation Loop (GOL)}

The concept of Generalized Operation Loop (GOL) is based on Operation Loop (OL). Tan Yuejin firstly proposed OL theory and defined the combat process as a closed loop consisting of one or more sensors, deciders, attack weapons and targets [6]. In the swarming UAVs combat system, in addition to the basic relationships in OL, there may be more relationships among the same kind of weapons. We add these relationships to the standard OL theory and define it as Generalized Operation Loop.

Definition 1: Generalized Operation Loop (GOL) is a modified closed loop based on traditional Operation Loop (OL), besides the cycle of sensors (S), decision-makers (D), attackers (A) and targets (T), it contains more weapon relationships, including the information sharing relationships between sensors, the coordination of command and control relationships between decision-makers, and the autonomous coordinated attack relationships between attackers.

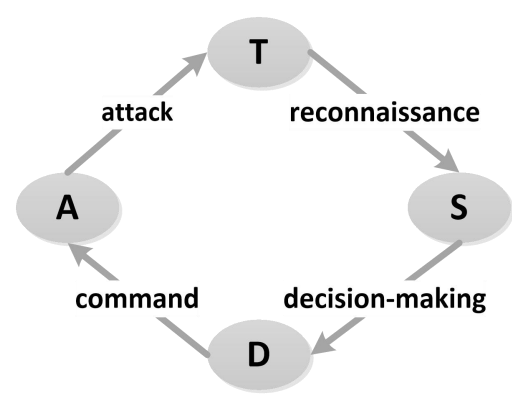

Fig. 1. Standard Operation Loop (OL).

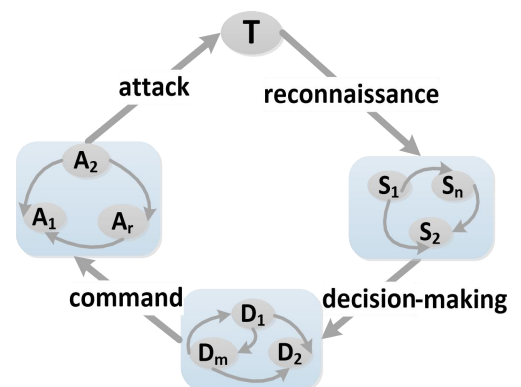

Fig. 2. Generalized Operation Loop (GOL).

\subsection{Nodes definition}

In the system network, the weapons are abstracted as nodes and can be classified as $V=\{S, D, A, T\}$. Where, $S, D, A, T$ represents the weapon of sensor, decider, attacker and target entity respectively. The attributes of the four types of nodes are set in figure 3-6. 


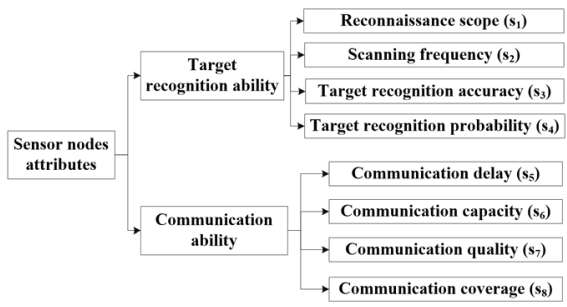

Fig. 3. Attributes of sensor nodes.

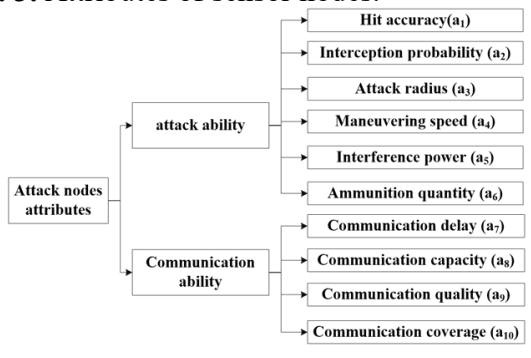

Fig. 5. Attributes of attack nodes.

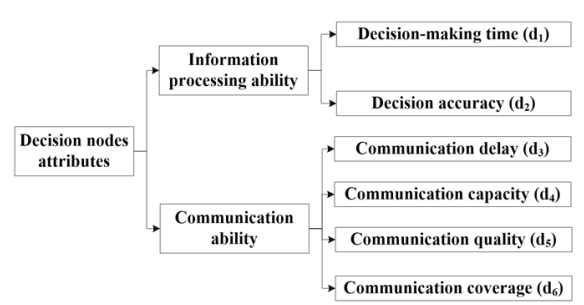

Fig. 4. Attributes of decision nodes.

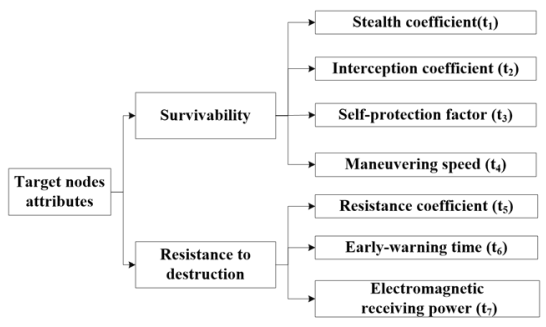

Fig. 6. Attributes of target nodes.

\subsection{Edges definition}

The types of edges represent different relationships between S, D, A and T nodes. This part aims to find out all the possible relationships (edge types) among the system weapons and give corresponding edge attributes for further effectiveness evaluation. During the modeling process, we mainly consider the information sharing and the complex communication relationships between UAVs.

\subsubsection{Edge types}

As shown in table 1, we carefully analyzed the relationships between S, D, A, and T, and the edges with practical meanings are listed.

Table 1. Edge classifications and meanings.

\begin{tabular}{|c|c|c|l|}
\hline Edge meanings & Edges & $\begin{array}{l}\text { Edge } \\
\text { direction }\end{array}$ & Interpretation \\
\hline Command edges & $D \rightarrow A$ & $\begin{array}{l}\text { One-way } \\
\text { Directed }\end{array}$ & $\begin{array}{l}\text { The command nodes can control the } \\
\text { actions of attack weapons and sensor } \\
\text { devices. }\end{array}$ \\
\hline Intelligence edges & $A \rightarrow D$ & $\begin{array}{l}\text { Directed } \\
\text { One-way }\end{array}$ & $\begin{array}{l}\text { This edge type represents the feedbacks } \\
\text { of battlefield information to the } \\
\text { decision nodes. }\end{array}$ \\
\hline Attack edge & $A \rightarrow T$ & $\begin{array}{l}\text { One-way } \\
\text { Directed }\end{array}$ & $\begin{array}{l}\text { It represents the attack task to the } \\
\text { target. }\end{array}$ \\
\hline Reconnaissance edge & $T \rightarrow S$ & $\begin{array}{l}\text { One-way } \\
\text { Directed }\end{array}$ & $\begin{array}{l}\text { The information of the targets can be } \\
\text { detected, and it means the information } \\
\text { flow from targets to sensors. }\end{array}$ \\
\hline
\end{tabular}




\begin{tabular}{|c|c|l|l|}
\hline $\begin{array}{c}\text { Command coordination } \\
\text { edge }\end{array}$ & $D \leftrightarrow D$ & Bidirectional & $\begin{array}{l}\text { This edge means the command } \\
\text { cooperation between the decision - } \\
\text { makers. }\end{array}$ \\
\hline Information sharing edge & $S \leftrightarrow S$ & Bidirectional & $\begin{array}{l}\text { It mainly represents the information } \\
\text { sharing between the reconnaissance } \\
\text { UAVs in the combat process. }\end{array}$ \\
\hline Attack coordination edge & $A \leftrightarrow A$ & Bidirectional & $\begin{array}{l}\text { It mainly represents the attack } \\
\text { cooperation between the attack UAVs } \\
\text { in the combat process. }\end{array}$ \\
\hline
\end{tabular}

\subsubsection{Edge attribute}

For the combat effectiveness evaluation, we define the edge attribute of the operational information entropy using the nodes attributes data of S, D, A and T. In 1948, Shannon proposed the concept of "information entropy" [7] and he described the information entropy as

$$
H=-\sum_{x \in U} P(x) \lg P(x)
$$

In the combat process, the low operational information uncertainty (also information entropy) means the better knowledge of the battle situation, which will help to get better combat effectiveness. Thus, we will use the information entropy to make the combat effectiveness evaluation and give the following modified edge operational information entropy definition.

Definition 2: Edge operational information entropy is used to reflect the information uncertainty of the information flow in the combat network, signifying the control and knowledge of battlefield situation, and is defined as $h_{e}$.

$$
\begin{gathered}
h_{e}=-\sum_{i=1}^{n} w_{i} \lg f_{i} \\
f_{i}=1-\frac{2}{e^{x_{i}}+e^{-x_{i}}}
\end{gathered}
$$

Supposing that the edge $e$ connects the nodes of $S_{1}$ and $S_{2}$, then $x_{i}(i=1,2, \ldots, n)$ represents the comprehensive index calculated from the attributes of $S_{1}$ and $S_{2} . n$ is the number of $x_{i}$ and $w_{i}$ is the weights of $x_{i} \cdot f_{i}$ is a membership function to guarantee $h_{e}>0$ (that is, $\log f_{i}<0, f_{i} \in[0,1]$ ). For different types of edges, there is a subtle difference in the number of $x_{i}$ and its calculation method, thus the edge operational information entropies will also be different slightly. Here we just take the $S \leftrightarrow S$ edge for example and give its edge operational information entropy calculation method. Supposing that there are two reconnaissance UAVs $\mathrm{S}_{1}$ and $\mathrm{S}_{2}$, which are all sensor nodes $(\mathrm{S})$ and their attributes are shown in figure 3. $x_{1}$ is set to mark whether there is a communication connect between the two UAVs, the information capacity of the communication link is set to be $x_{2}$, the information quality of the communication link is $x_{3}$, and $x_{4}$ means the information transmission delay, then

$$
\begin{gathered}
x_{1}=\left\{\begin{array}{l}
1, d_{S_{1} S_{2}} \leq \min \left(s_{8}^{1}, s_{8}^{2}\right) \\
0, d_{S_{1} S_{2}} \leq \min \left(s_{8}^{1}, s_{8}^{2}\right)
\end{array}\right. \\
x_{2}=\min \left(s_{6}^{1}, s_{6}^{2}\right), x_{3}=s_{7}^{1} \times s_{7}^{2}, x_{4}=s_{5}^{1}+s_{5}^{2}
\end{gathered}
$$




$$
h_{e, S_{1} S_{2}}=-\sum_{i=1}^{4} w_{i} \lg \left(1-\frac{2}{e^{x_{i}}+e^{-x_{i}}}\right)
$$

where, $d_{S_{1} S_{2}}$ means the distance of UAV $\mathrm{S}_{1}$ and $\mathrm{S}_{2}, s_{j}^{1}$ and $s_{j}^{2}$ represent the attributes of node $\mathrm{S}_{1}$ and $\mathrm{S}_{2}$, as figure 3 shows. $w_{i}$ is the weight of $x_{i} \cdot h_{e, S_{1} S_{2}}$ is the operational information entropy of the edge $S \leftrightarrow S$, meaning the information uncertainty and reflecting the combat effectiveness.

\section{The operational effectiveness evaluation for the swarming UAVs air combat system}

Based on the above network model, we put forward the concept of Operation Loop Capability and evaluate the target-attack effectiveness of the swarming UAVs air combat system.

Definition 3: Operation Loop Capability is an index to quantify the impact of a certain Operation Loop (both standard and generalized loop) to a particular target in the combat system network.

As is mentioned in 2.4.2, the edge operational information entropy is a measure of the combat information uncertainty. A low operational information entropy means smaller information uncertainty of the target and will lead to stronger combat capability. Therefore, there is an inverse relationship between the information entropy and the combat capability. Hence, we define

$$
C_{k}=e^{-h_{e, k}}(k=1,2, \ldots, m)
$$

where $m$ is the number of edges of one Operation Loop, $C_{k}$ represents the capability of the $\mathrm{k}_{\mathrm{th}}$ edge in the Operation Loop, $h_{e, k}$ is the operational information entropy of the $\mathrm{k}_{\mathrm{th}}$ edge in the Operation Loop. Then the Operation Loop Capability $\left(C_{O L}\right)$ can be calculated by:

$$
C_{O L}=\prod_{k}^{m} C_{k}
$$

Supposing that an attack is launched to target $p$, the number of participated operational loops is $r$, then the striking effectiveness to $p$ is equal to the sum of the combat capabilities of all the corresponding operational loops. Namely,

$$
C_{T_{p}}=\sum_{j=1}^{r} C_{O L j}
$$

Definition 4: The target-attack effectiveness of the swarming UAVs air combat system $(C)$ is the sum of the striking capabilities to all targets.

$$
C=\sum_{p=1}^{l} w_{p} C_{T_{p}}
$$

where $l$ is the number of the targets in the system, $w_{p} \in[0,1]$ is the weights of the targets based on target threat degree ranking. $w_{p}$ can be calculated TOPSIS method [8] based on target attributes data.

\section{Case study}

In this part, we take the attack to enemy ground command centers and infrastructures as an example. 


\subsection{Network model}

To build the system network model, we have to figure out all the combat weapons and clarify their types. The weapons in the swarming UAVs air combat scene are listed in table 2.

Table 2. The corresponding weapons in the swarming UAVs air combat system.

\begin{tabular}{|c|c|l|}
\hline Entities & $\begin{array}{c}\text { Nodes } \\
\text { type }\end{array}$ & \multicolumn{1}{c|}{ Weapons and quantities } \\
\hline Sensors & $\mathrm{S}$ & $\begin{array}{l}\text { Ground radar station (1); Electronic reconnaissance aircraft (Y-8, } \\
\text { 1); Reconnaissance UAVs (7) }\end{array}$ \\
\hline Deciders & D & Early warning aircraft (KJ-2000,1) \\
\hline Attackers & A & $\begin{array}{l}\text { Attack UAVs (8); Fighter plane (J-10, 3); Bombers (H-6, 2); } \\
\text { Attack plane (Q-5, 1); Air-to-ground guided missile (1); Cruise } \\
\text { missile (1); Aerial artillery (1); Airborne antimissile system (1) }\end{array}$ \\
\hline Targets & $\mathrm{T}$ & $\begin{array}{l}\text { Fighter plane (S-30,1); Fighter plane (F-15,1); Interceptor plane (F- } \\
\text { 106,1), Enemy command post (1); Enemy airport (1); Detection } \\
\text { radar (1); Guidance radar (1); Missile launch location (1); } \\
\text { Antiaircraft gun launch location (1); Air-to-ground guided missile } \\
\text { (1); Antiaircraft gun (1); Interceptor missile (Patriot 3, 1) }\end{array}$ \\
\hline
\end{tabular}

The second step of the network model is to determine edges among the above weapons. The attack weapons undertake the combat mission to the enemy and the strike relationships are as follows:

Table 3. Attack relationships.

\begin{tabular}{|c|l|l|l|}
\hline Weapons & Enemy targets & Weapons & Enemy targets \\
\hline J-10 & F-15 & Cruise missile & S-30; F-106; F-15; Command post; Airport \\
\hline J-10 & S-30 & $\begin{array}{l}\text { Air-to-ground } \\
\text { guided missile }\end{array}$ & $\begin{array}{l}\text { Airport; Command post; Missile launch } \\
\text { location; Antiaircraft gun launch location }\end{array}$ \\
\hline J-10 & F-106 & $\begin{array}{l}\text { Reconnaissan } \\
\text { ce UAVs }\end{array}$ & $\begin{array}{l}\text { S-30; Command post; Airport; Missile } \\
\text { launch location; Antiaircraft gun launch } \\
\text { location }\end{array}$ \\
\hline H-6 & $\begin{array}{l}\text { Command post; } \\
\text { Airport; Antiaircraft } \\
\text { gun launch location }\end{array}$ & Attack UAVs & $\begin{array}{l}\text { S-30; F-15; F-106; Command post; } \\
\text { Airport; Antiaircraft gun; Air-to-ground } \\
\text { guided missile; Antiaircraft gun launch } \\
\text { location; Missile launch location; Patriot 3 }\end{array}$ \\
\hline H-6 & $\begin{array}{l}\text { Command post; } \\
\text { Airport; Missile } \\
\text { launch location }\end{array}$ & $\begin{array}{l}\text { Aerial } \\
\text { artillery }\end{array}$ & S-30; F-106; F-15; Command post \\
\hline lissile launch \\
$\begin{array}{l}\text { gun launch location; } \\
\text { Detection radar; } \\
\text { Guidance radar }\end{array}$ & $\begin{array}{l}\text { Airborne } \\
\text { antimissile } \\
\text { system }\end{array}$ & $\begin{array}{l}\text { Patriot 3; Antiaircraft gun; Air-to-ground } \\
\text { guided missile }\end{array}$ \\
\hline
\end{tabular}




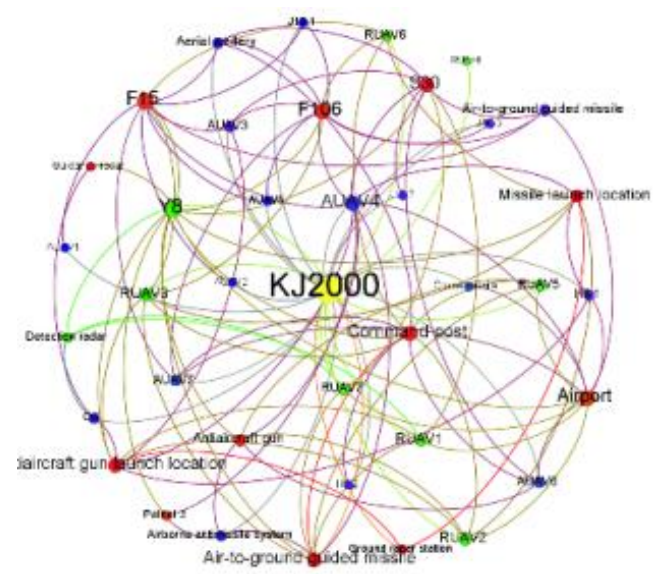

Fig. 7. Due to the large number of nodes, we merely listed the attack relationships in table 3 , and other relationships are shown as the edges in the left operational network. The green, yellow, blue and red nodes represent sensors, deciders, attackers and targets respectively. All the edges in the network are divided into nine edge types, as table 1 shows.

\subsection{Operational effectiveness evaluation}

The effectiveness of the swarming UAVs air combat system $(C)$ is defined as the sum of the striking capabilities to all targets, so we have to firstly calculate the operational effectiveness to a certain target. Just take the target of "Antiaircraft gun launch location" as an example, table 4 shows its attribute data. Notably, all the weapon attributes' (as figure 36) data is from relevant literatures or Internet, and due to the space limitation, we didn't list all the data.

Table 4. Data of "Antiaircraft gun launch location".

\begin{tabular}{|c|c|c|c|c|c|c|c|}
\hline Attributes & $\mathrm{t}_{1}$ & $\mathrm{t}_{2}$ & $\mathrm{t}_{3}$ & $\mathrm{t}_{4}$ & $\mathrm{t}_{5}$ & $\mathrm{t}_{6}$ & $\mathrm{t}_{7}$ \\
\hline Values & 3 & 4 & 3 & 0 & 6 & 0.5 & 4 \\
\hline
\end{tabular}

Aimed at the target of "Antiaircraft gun launch location", one of the operational loops in the network is "Antiaircraft gun launch position $\rightarrow \mathrm{Y}-8 \rightarrow \mathrm{KJ}-2000 \rightarrow \mathrm{H}-6$ $\rightarrow$ Antiaircraft gun launch position". In this loop, the edge types including $\mathrm{S} \rightarrow \mathrm{D}, \mathrm{D} \rightarrow \mathrm{A}, \mathrm{A} \rightarrow \mathrm{T}$ and $\mathrm{T} \rightarrow \mathrm{S}$. According to the attribute data of these weapons, the operational information entropies of the four edges are calculated.

$$
\begin{gathered}
h_{e, T S}=x_{0} \times\left[-\sum_{i=1}^{7} \frac{1}{7} \lg \left(1-\frac{2}{e^{x_{i}}+e^{-x_{i}}}\right)\right]=0.18033 \\
h_{e, S D}=-\sum_{i=1}^{4} 0.25 \lg \left(1-\frac{2}{e^{x_{i}}+e^{-x_{i}}}\right)=0.88768 \\
h_{e, D A}=-\sum_{i=1}^{4} 0.25 \lg \left(1-\frac{2}{e^{x_{i}}+e^{-x_{i}}}\right)=0.79973 \\
h_{e, A T}=x_{0} \times\left[-\sum_{i=1}^{5} 0.2 \lg \left(1-\frac{2}{e^{x_{i}}+e^{-x_{i}}}\right)\right]=0.15888
\end{gathered}
$$

Then the capability of this Operation Loop is 


$$
C_{O L}=\prod_{k}^{m} C_{k}=\prod_{k}^{m} e^{-h_{e, k}}=e^{-\left(h_{e, T S}+h_{e, S D}+h_{e, D A}+h_{e, A T}\right)}=0.1318
$$

After a series of calculations of all the Operation Loops including the target "Antiaircraft gun launch location", the operational effectiveness to this target $C_{T_{p}}$ is summed to be 211.3263 .

Table 5. The operational effectiveness to all targets.

\begin{tabular}{|c|c|c|c|c|c|c|}
\hline Targets & $\begin{array}{c}\text { Antiaircraft } \\
\text { gun launch } \\
\text { location }\end{array}$ & $\begin{array}{c}\text { Missile } \\
\text { launch } \\
\text { location }\end{array}$ & S-30 & F-106 & F-15 & $\begin{array}{c}\text { Comman } \\
\text { d post }\end{array}$ \\
\hline$w_{p}$ & 0.0441 & 0.0441 & 0.0871 & 0.0954 & 0.0911 & 0.1231 \\
\hline$C_{T_{p}}$ & 211.3263 & 146.6069 & 175.8427 & 284.4926 & 367.9419 & 234.7211 \\
\hline Targets & Airport & $\begin{array}{c}\text { Detection } \\
\text { radar }\end{array}$ & $\begin{array}{c}\text { Guidance } \\
\text { radar }\end{array}$ & $\begin{array}{l}\text { Air-to-ground } \\
\text { guided } \\
\text { missile }\end{array}$ & $\begin{array}{c}\text { Antiaircraf } \\
\text { t gun }\end{array}$ & Patriot 3 \\
\hline$w_{p}$ & 0.0986 & 0.1380 & 0.1454 & 0.0472 & 0.0392 & 0.0472 \\
\hline$C_{T_{p}}$ & 403.524 & 27.63429 & 8.97049 & 104.0399 & 135.9472 & 61.2898 \\
\hline
\end{tabular}

Table 5 illustrates the operational effectiveness to all targets in the swarming UAVs air combat system and the system combat effectiveness $C$ can be certified as

$$
C=\sum_{p=1}^{l} w_{p} C_{T_{p}}=178.6749
$$

Although the proposed system combat effectiveness index is a figure and sometimes cannot be certified, it provides a quantitative method of assessing the swarming UAVs combat scene. Besides, it may live a foundation for weapon contribution or importance evaluation by changing node quantities.

\section{Conclusion}

In this paper, we propose an operational effectiveness evaluation method of the swarming UAVs air combat system. Before the effectiveness evaluation, the system network model is firstly established. Considering the unique weapon relationships in UAVs system, the concept of Generalized Operation Loop (GOL) is put forward and the edge operational information entropy is proposed to reflect the information uncertainty and combat effectiveness based on the network nodes attributes. As for the system operational effectiveness evaluation, we mainly focus on the striking capability and give the concept of Operation Loop Capability to evaluate the system target-attack effectiveness, which can be calculated from the edge operational information entropies. The combat effectiveness of the swarming UAVs air combat system is represented by the sum of the striking capabilities to all targets. Finally, the scene of swarming UAVs air combat is taken as a case study to apply and verify the proposed operational effectiveness evaluation method. It provides a good quantitative perspective for swarming UAVs system performance assessment and can help to evaluate weapon contribution or importance.

In the future works, we will make a further analyzation of the equipment importance in the system and their influence on the network structure invulnerability. 


\section{Acknowledgments}

The work was supported by the National Natural Science Foundation of China under Grant 71571185; and the Research Project of National University of Defense Technology under Grant 15GJ003-278.

\section{References}

1. Bitzinger R. US-China Competition, the Third Offset Strategy, and Implications for the Global Arms Industry[J]. Institute on Global Conflict \& Cooperation Working Paper, 2017.

2. Shen Chao, Wu Kunlin and Song Yiran. Key developments in the development of drone bee colony operations[J]. Aerospace Missile, 2016(11): 28-33.

3. Shen Taoran and Sang Yiyong. Overview of the development of foreign UAV equipment and typical combat modes [J]. New Industrialization, 2018(5).

4. Cares J R, Incorporated A. An information age combat model [J]. Paper for Iccrts, 2004.

5. Cares J R. LCS Study - design principles of distributed, networked forces[J]. 2005.

6. Tan Yuejin. Principles of systems engineering (Revised edition) [M]. Beijing: Science Press, 2010. 6-22.

7. Shannon C E. A mathematical theory of communication[J]. Bell Labs Technical Journal, 1948, 27(4):379-23.

8. Deng H, Yeh C H, Willis R J. Inter-company comparison using modified TOPSIS with objective weights[J]. Computers \& Operations Research, 2000, 27(10):963-973. 